\title{
O LUGAR DA MILITÂNCIA NA CONSTRUÇÃO DA EDUCAÇÃO EM SAÚDE: ANÁLISE COM BASE EM UMA POLÍTICA REGIONAL DE EDUCAÇÃO PERMANENTE
}

\author{
THE PLACE OF MILITANCE IN THE CONSTRUCTION OF HEALTH EDUCATION: \\ ANALYSIS BASED ON A REGIONAL POLICY OF PERMANENT EDUCATION
}

\author{
EL LUGAR DE LA MILITANCIA EN LA CONSTRUCCIÓN DE LA EDUCACIÓN EN SALUD: \\ ANÁLISIS CON BASE EN UNA POLÍTICA REGIONAL DE EDUCACIÓN PERMANENTE
}

\author{
Maria Raquel Pilar Steyer ${ }^{1}$ \\ Marco André Cadoná ${ }^{2}$
}

Resumo $\mathrm{O}$ artigo apresenta uma análise sobre a importância da militância na construção de uma política pública regional de educação permanente. Ao tomar como referência a atuação política de participantes da Comissão de Integração Ensino-Serviço, na Região 28 de Saúde, no Rio Grande do Sul, a análise dá atenção ao espaço político que os participantes da Comissão ocupam não somente na articulação política, mas, também, na própria execução de ações relacionadas à educação permanente em saúde na região pesquisada. Sob o ponto de vista metodológico, a pesquisa da qual resultou este artigo foi realizada com base em dois procedimentos principais: levantamento e análise de dados secundários que abrangeram legislações relacionadas à política de educação permanente em saúde e a estruturação da Comissão de Integração EnsinoServiço; realização de entrevistas semiestruturadas com participantes da Comissão da Região 28 de Saúde do Rio Grande do Sul. Como resultado, verificou-se que, embora a Comissão de Integração Ensino-Serviço tenha sido instituída pela legislação com funções apenas consultivas no âmbito das regiões de saúde, a atuação comprometida dos seus participantes na Região 28 de Saúde consegue transformá-la num importante espaço (regional) de militância e de execução de políticas de educação permanente em saúde.

Palavras-chave militância; políticas públicas; regionalização da saúde; educação permanente em saúde.
Abstract The article presents an analysis about the importance of militancy in the construction of a regional public policy of permanent education. Taking as a reference the political action of participants of the Commission for Integration Teaching-Service, in Region 28 of Health, in Rio Grande do Sul, Brazil, the analysis gives attention to the political space that Comission participants occupy not only in the political, but also in the execution of actions related to permanent health education in the region. From the methodological point of view, the research was based on two main procedures: survey and analysis of secondary data, which covered legislation related to the policy of permanent education in health and the structuring of Commission for Integration TeachingService; semi-structured interviews with Commission for Integration Teaching-Service participants from Region 28 of Health of Rio Grande do Sul. As a result, it was verified that, although the Commission for Integration Teaching-Service was established by legislation with only advisory functions within the health regions, the committed performance of its participants in Region 28 of Health of Rio Grande do Sul is able to transform it into an important space (regional) of militancy and execution of policies of permanent education in health. Keywords militancy; public policy; regionalization of health; permanent health education.

(cc) BY Este é um artigo publicado em acesso aberto sob uma licença Creative Commons. 


\section{Introdução}

Desde a sua criação, o Sistema Único de Saúde (SUS) apresentou diferentes desafios relacionados ao trabalho e aos trabalhadores em saúde. Assim, nas concepções e propostas dos sujeitos sociais e políticos que protagonizaram o movimento pela Reforma Sanitária que resultaria na criação do SUS, havia expectativa de um trabalhador de saúde comprometido, engajado, participativo e com habilidades para atuar em equipe, com uma visão ampliada do conceito de saúde (Paim, 2008). E a perspectiva de uma gestão participativa, de um trabalho em equipe, de uma concepção de saúde voltada à promoção da saúde colocou a necessidade de uma qualificação profissional dos trabalhadores em saúde comprometidos com pressupostos e objetivos do SUS.

A Política Nacional de Educação Permanente em Saúde, institucionalizada já nos anos 2000, inseriu-se naquele contexto histórico de discussão e de implementação de políticas de qualificação dos trabalhadores em saúde. A construção daquela política representou o esforço em cumprir uma das metas da saúde coletiva no Brasil: tornar a rede pública de saúde uma rede de ensino-aprendizagem no trabalho e no exercício da prática profissional.

O Ministério da Saúde, ao publicar a portaria n. 1.996/2007, que dispôs "sobre as diretrizes para a implementação da Política Nacional de Educação Permanente em Saúde" (Brasil, 2007), atribuiu aos Colegiados de Gestão Regional, compostos "pelos gestores municipais de saúde do conjunto de municípios de uma determinada região de saúde e por representantes do(s) gestor(es) estadual(ais)", o planejamento regional para a educação permanente em saúde. A estes colegiados foi dada a prerrogativa de definição das prioridades, das responsabilidades de cada ente e do apoio para o processo de planejamento local/regional (Brasil, 2007), embora atribua também grande importância para as CIESs, apesar de suas funções consultivas.

Com base na discussão de uma política de educação permanente em saúde no Brasil, com ênfase no caráter regional que ela tomou desde a primeira década do século XXI, pretende-se analisar o espaço político da militância de participantes da Comissão de Integração Ensino-Serviço (CIES) na construção de uma política de educação em saúde na Região 28 de Saúde, no Rio Grande do Sul.

\section{A política pública como construção sociopolítica}

Tomar a política pública como uma 'construção sociopolítica' é pressupor, em primeiro lugar, que a própria realidade é construída mediante ações concretas de sujeitos sociopolíticos, situadas em determinado espaço e em determinado tempo. Nessa direção, uma política pública não é o resultado apenas da ação 
governamental, nem expressa necessariamente uma dinâmica de consensos em torno de problemas que certa coletividade enfrenta ou de soluções necessárias e possíveis para esses problemas. Uma política pública, quando construída em regimes democráticos, expressa processos políticos que pressupõem a institucionalização de espaços de participação sociopolíticos capazes de garantir a representação da complexidade de interesses sociais que compõem uma mesma sociedade.

No Brasil, a maior visibilidade das políticas públicas, inclusive como objeto de estudos nas ciências sociais, impulsionou um debate profícuo, com a participação de diferentes perspectivas teóricas e metodológicas que, ao mesmo tempo que permitem que as políticas públicas sejam analisadas com base em diferentes conceitos e diferentes modelos de análise, tornam a própria definição de políticas públicas uma tarefa mais complexa. Souza (2006) aponta essa complexidade, ao afirmar que "não existe uma única, nem melhor, definição sobre o que seja política pública", indicando que as políticas públicas podem ser definidas "como um campo dentro do estudo da política que analisa o governo à luz de grandes questões públicas", ainda que, segundo a autora, “a definição mais conhecida continua sendo" aquela que sustenta que "decisões e análises sobre política pública implicam responder às seguintes questões: quem ganha o quê, por que e que diferença faz" (Souza, 2006, p. 24).

Para diferentes teóricos das políticas públicas, a complexidade dos padrões de interações sociais envolvidos na formulação e na gestão das políticas públicas requer a adoção de modelos do processo de decisão que levam à sua institucionalização (Flexor e Leite, 2006). Para esses teóricos, tais modelos simplificam e esclarecem o entendimento sobre políticas públicas, em especial quando os mesmos permitem descobrir diferentes momentos de construção de uma política, o que garante um maior conhecimento sobre o processo político como um todo (Flexor e Leite, 2007).

Dentre os modelos que são adotados para a análise da dinâmica sociopolítica implicada na construção de políticas públicas encontra-se o instrumento analítico do policy cycle, ou o modelo de 'ciclo de políticas'. De acordo com esse instrumento analítico, as políticas públicas expressam uma sequência de atividades, desde o nascimento de um problema até a adoção e a avaliação das ações que visem resolvê-lo. Cada fase caracteriza-se por atividades concretas, realizadas por diferentes sujeitos sociopolíticos e pelos agentes públicos (o trabalho legislativo; o processo decisório em gabinetes ministeriais; a gestão burocrática das medidas adotadas etc.).

Na perspectiva do 'ciclo de políticas', o primeiro passo para o desenvolvimento de uma política pública é a 'definição de problemas', quando manifestam as demandas. Quando um problema é identificado e analisado, possíveis soluções são exploradas por meio de pesquisa e análise para a ação governamental. Sua identificação envolve a percepção de sujeitos sociopolíticos 
e a definição do problema "pelos quais são norteados o conjunto de causas, soluções, obstáculos e avaliações" (Secchi, 2013, p. 35).

A 'formação da agenda' é um segundo passo e expressa o processo através do qual as demandas dos diversos grupos da população entram na lista de prioridades e são transformadas em assuntos que disputam atenção das autoridades públicas. As prioridades do processo de construção da agenda são estabelecidas por sujeitos sociopolíticos, classificados por 'atores individuais' e 'atores coletivos'. Os primeiros são pessoas que agem intencionalmente em uma arena política (como os políticos, burocratas, magistrados, e os formadores de opinião). Já os 'atores coletivos' são grupos e organizações que agem com um propósito determinado em uma arena política (como os partidos políticos, burocracia, grupos de interesse, organizações da sociedade civil, movimentos sociais etc.), que definem e decidem questões fundamentais no desenvolvimento do processo de formulação de alternativas das políticas pública (Secchi, 2013).

A terceira etapa para o desenvolvimento de uma política pública é a 'formulação de alternativas', quando se inicia uma fase na construção de políticas públicas que define seu objetivo, os programas que serão desenvolvidos, as metas a serem alcançadas e os recursos a serem empregados. Nesta fase, os sujeitos sociopolíticos decidem o que vão defender, o que envolve não apenas a escolha, mas a preparação das alternativas de tal escolha (Secchi, 2013, p. 37).

A quarta fase trata da 'tomada de decisão'. O desenvolvimento deste processo em uma política pública considera a transformação de um problema em solução, e leva em conta as ações, intervenções e estratégias que sustentam os estudos, conflitos e construção de coalizões, dentre outros. É quando se desenham as metas que se pretende atingir, os recursos a serem empregados e o processo de intervenção (Flexor e Leite, 2007).

A quinta fase é a 'implementação de políticas', que se traduz na operacionalização da política pública em planos, programas e projetos no âmbito da burocracia pública, bem como a sua execução. Este é um momento em que o planejamento é transformado em ação, considerado por alguns autores como a fase de responsabilidade administrativa da política com aplicação da ação direta, o controle e monitoramento das medidas definidas (Secchi, 2013).

A 'avaliação das políticas públicas' é a sexta e última fase do ciclo das políticas públicas. É um instrumento voltado para subsidiar a tomada de decisão nos diversos momentos que ocorre ao longo das fases, e quando são avaliados os resultados alcançados com a implementação das propostas e dos programas de governo, com o intuito de conhecer melhor o estado da política e o nível de redução do problema que a gerou, com correção de ações (Pinto, 2008).

Para os fins deste estudo, a teoria do ciclo de política pública ganha importância, em primeiro lugar, como um instrumento metodológico pelo qual se pretende melhor identificar o espaço político que a CIES tem na dinâmica sociopolítica de construção das políticas de educação permanente numa dada 
Região de Saúde; e preocupa-se com a análise das possibilidades e das dificuldades de atuação (dos militantes da referida comissão) nas diferentes fases de construção das políticas públicas de educação permanente.

Mas, por outro lado, é importante destacar que alguns autores da teoria do ciclo da política pública enfatizam duas questões fundamentais na análise da construção de políticas públicas: de onde surgem as demandas e quem participa do processo de definição da agenda (Pinto, 2008, p. 29). Nessa direção, trata-se de uma perspectiva teórica que problematiza o processo político no qual determinados problemas ganham visibilidade, tornando-se relevantes para a definição da formulação da agenda das políticas públicas. Como assinala Pinto (2008),

um assunto ou tema para atingir o status de agenda precisa ser alvo de atenções e envolve a interação de uma série de elementos complexos que influenciam a decisão, formulação e implementação das políticas públicas (Pinto, 2008, p. 29).

Trata-se, portanto, de uma construção sociopolítica, pois decorre de ações e interações que diferentes sujeitos sociais e políticos, que representam tanto complexos interesses da sociedade civil quanto interesses governamentais, estabelecem ao se colocarem como participantes na construção de políticas públicas.

E, nesse sentido, destaca a importância de 'quem participa' na construção das políticas públicas, e envolve aqui tanto as ações do Estado (governos e burocracia estatal) quanto as ações de indivíduos, grupos sociais, instituições sociais, segmentos sociais, e mesmo classes sociais. Abre, assim, uma problematização acerca da própria participação sociopolítica na construção das políticas públicas, na medida em que ela pode ser limitada a uma instituição ou espaço governamental. E, por outro lado, pode ser resultado de diferentes tipos de participação que provêm de espaços fora do governo.

\section{A região como território de militância na construção de políticas públicas de saúde}

Após a promulgação da Constituição Federal de 1988, a descentralização se constituiu num instrumento de expansão da lógica democrática, o que possibilitou a criação de novas instâncias de negociação, e determinou um novo formato organizacional das atividades estatais no Brasil. Esta organização passou a pressupor novas relações entre instituições nacionais, regionais e municipais, públicas ou privadas, para resolver os problemas da população brasileira, direcionados para descentralização, como uma das condições da mudança implementada nesse novo modelo de política pública, em oposição ao modelo até então dominante, centralizado, burocratizado e excludente (Escorel, 2008). 
Destaque-se, portanto, que a partir da década de 1990 o Brasil tem uma política de Estado na área de saúde que consagrou alguns princípios fundamentais; cabe enfatizar os princípios da 'participação da população' e da 'regionalização' de forma integrada. Mediante a instituição de um conjunto de leis, portarias e decretos, que determinou regras e mecanismos em todo o território nacional, a regionalização tornou-se uma diretriz do SUS e um eixo estruturante do Pacto de Gestão, que devia orientar a descentralização das ações e serviços de saúde e os processos de negociação e de pactuação entre os gestores. Essa direção está presente na definição de regionalização adotada pelo Ministério da Saúde, que a define como "recortes territoriais inseridos em espaços contínuos (...) tendo como base a existência de identidades culturais, econômicas e sociais, assim como de redes nas áreas de comunicação, infraestrutura, transportes e saúde" (Brasil, 2006, p. 23).

É importante registrar, também, que o decreto 7.508/2011 regulamentou a Lei Orgânica de Saúde, garantindo uma sintonia nacional, uma unicidade organizativa e uma coesão entre os pensamentos dos dirigentes da saúde pública brasileira. O referido decreto trata de alguns temas, em especial daqueles que dizem respeito à organização e funcionamento administrativo-sanitário do SUS, assentados na regionalização e hierarquização dos serviços (Brasil, 2011).

Sob o ponto de vista da educação permanente em saúde, foi desde a divulgação, pelo Ministério da Saúde, do Pacto pela Saúde, em 2006, que a questão da regionalização ganhou maior visibilidade e importância. Por meio daquele Pacto, o Ministério da Saúde publicou a portaria n. 1.996, que afirmou a necessidade de uma política nacional de educação permanente em saúde comprometida com "as especificidades regionais" e "a superação das desigualdades regionais", e atribuiu a condução regional da política de educação permanente em saúde aos "Colegiados de Gestão Regional", "com a participação das Comissões de Integração Ensino-Serviço (CIES)” (Brasil, 2007).

Naquele contexto, então, foram instituídas as CIESs, que se estabeleceram como um espaço político (regional) estratégico na formulação, na condução e no desenvolvimento da Política de Educação Permanente em Saúde. E ao atribuir importância aos municípios, aos Colegiados de Gestão Regional e às Comissões de Integração Ensino-Serviço na construção da política pública de educação em saúde, as políticas nacionais criaram condições históricas importantes para que essas políticas públicas passassem não somente a ser discutidas nos âmbitos locais e regionais, mas, também, para que fomentassem uma atuação política e social, de indivíduos e instituições sociopolíticas, a partir do recorte regional. A região passou a ser um importante condicionamento territorial da militância política, pois se constituiu como espaço/tempo ao desenvolverem dinâmicas históricas de construção das políticas públicas de educação em saúde.

No entanto, para estabelecer uma definição de militância, a primeira percepção é de que, mesmo no 'senso comum', a palavra militância muitas vezes 
remete à ideia de 'engajamento político' a determinadas causas (que podem ser a questão da saúde, a questão ambiental ou outras temáticas que traduzem preocupações e/ou problemas sociais). Militância tem seu significado no agir, de forma contínua, com vistas a uma mudança social; militante é o agente que atua ativamente em favor de uma causa; ou ação que se posiciona a partir de uma concepção de mundo; que se identifica, diretamente e ativamente, com esta causa.

Embora as definições presentes no senso comum não sejam completamente inadequadas, elas podem resultar em imprecisões. Afinal, indivíduos podem estar 'engajados' na luta em favor de uma política de educação permanente em saúde sem que sejam 'militantes dessa causa'.

Para Reis, a discussão em torno do conceito de militância precisa partir de uma importante distinção entre "contestação", "engajamento" e "militantismo" (Reis, 2007, p. 9). Segundo a autora, a "contestação" é mais "conjuntural" e "situacional", pois remete a ações de "oposição ou negação de algo definido, seja uma situação, seja uma ideia em processo de afirmação" (Reis, 2007, p. 10); já "engajamento" remete a "atuações mais contínuas no tempo e no espaço", referindo-se à "disposição dos agentes para tomar posição sobre 'temas' e 'problemas' variados a partir de domínios igualmente diversos" (Reis, 2007, p. 10), o que significa que "estar engajado" implica "um sentido de intervenção e de inserção na realidade" que define as ações do agente engajado (Reis, 2007, p. 10). A noção de "militantismo", embora implique "atuações mais contínuas no tempo e no espaço", é mais complexa, pois, ao mesmo tempo em que abrange as outras duas noções (engajamento e contestação), se diferencia das mesmas, na medida em que compreende uma “dedicação sistemática a uma 'causa' ou 'organização'” (Reis, 2007, p. 10). Nessa direção, a noção de militantismo compreende mais do que "adesão a uma causa" (ser militante) ou ao rótulo que define a sua própria essência (militância), implicando processos que envolvem "mecanismos de socialização", "formas de engajamento", "sentidos atribuídos às 'causas'", modalidades de "investimentos oferecidos" e de "recompensas extraídas", padrões de atuação (Reis, 2007, p. 10).

Esta discussão (conceitual) torna-se fundamental para a definição do que se pretende com o conceito de 'militância' para se referir à atuação sociopolítica dos participantes da CIES da $28^{a}$ Região de Saúde na construção (regional) de uma política pública de educação em saúde.

O conceito de militância não remete a ações de 'contestação' e a participações esporádicas, descontínuas, efêmeras, contingentes dos agentes na discussão ou na implementação de políticas públicas de educação em saúde (como, por exemplo, podem ocorrer com representantes dos governos municipais que, pelo cargo que ocupam, se colocam como 'comprometidos' com a temática da educação permanente em saúde). A militância também não implica 
apenas um 'engajamento' com determinadas ações, uma intervenção ou uma disposição para atuar em favor de uma causa, ainda que de forma contínua (como ocorre, na CIES, com a participação de representantes de um mandato de gestão municipal no campo das políticas de educação em saúde). A militância, mais do que uma disposição contínua, implica uma 'dedicação' sociopolítica, compreende um 'envolvimento pessoal', uma trajetória de atuação e, acima de tudo, uma socialização, ou seja, todo um leque de experiências, de posicionamentos, de saberes, de práticas, de interações, de comunicações, de atividades desenvolvidas em determinado meio, permitindo que os indivíduos se constituam sujeitos (desenvolvam necessidades, capacidades, competência do agir, qualidades pessoais, visões de mundo) de uma determinada causa. O que significa dizer que a atuação dos militantes em educação permanente em saúde, por exemplo, na Região, ocorre (se materializa) através das trajetórias nos municípios, nas instituições específicas que se dedicam ao debate e à construção de políticas públicas nas redes sociais que se constituem mediante a participação nesses diferentes espaços. Mas, ao mesmo tempo, se materializa nos desafios, nos conflitos, nas possibilidades de consensos, nas expectativas e nas perspectivas de construção de uma política (regional) de educação permanente em saúde.

\section{Militância e participação da CIES na construção de uma política de educação permanente em saúde na Região 28 de Saúde}

Como espaço de discussão, mas, fundamentalmente, de construção das políticas públicas de educação permanente em saúde, as CIESs se apresentam como espaços/tempos de militância política e social e não são constituídas apenas por gestores da saúde, mas, também, por trabalhadores da saúde que podem ou não estar vinculados a movimentos sociais comprometidos com a defesa de questões relacionadas à saúde coletiva. Disso decorre a possibilidade de trabalhadores, em condições diferentes como representantes de movimentos sociais, de instituições de ensino, e das gestões municipais da saúde), estabelecerm uma história de participação política em defesa da educação permanente em saúde e desenvolverem uma militância política nesta temática.

A realização da pesquisa que embasou este artigo ocorreu com a utilização de duas frentes de levantamento de dados: os dados secundários, que abrangeram um estudo sobre as legislações relacionadas à política de educação permanente em saúde e à estruturação da CIES; e os dados primários, que, além do levantamento de documentos da CIES da Região 28 de Saúde, compreenderam também a realização de entrevistas (semiestruturadas) com pessoas que, no período analisado, ocupavam algum espaço político relacionado às políticas de educação em saúde na Região. 
Entre 27 pessoas entrevistadas, 11 foram secretários de saúde, contemplando, portanto, a grande maioria dos municípios que compõem a Região 28 de Saúde; 7 trabalhadores de saúde e participantes na CIES como representantes das gestões municipais; 3 participantes da CIES como representantes dos movimentos sociais (movimento estudantil, pastoral da saúde e pastoral da mulher); e 6 trabalhadores de saúde e participantes da CIES. Todos os entrevistados foram esclarecidos quanto aos objetivos da pesquisa, além da importância da participação nela e da garantia das condições éticas, conforme o termo de consentimento e as condições de realização definidas pelo Comitê de Ética em Pesquisa da Universidade de Santa Cruz do Sul (Unisc), órgão para o qual o projeto da pesquisa foi encaminhado e aprovado, sob o parecer número 1.155.032, de 21/07/2015.

Sob o ponto de vista da participação dos entrevistados na CIES, os gestores não participavam efetivamente na Comissão, embora fossem os responsáveis pelas indicações das representações municipais. Dos sete trabalhadores de saúde que participavam da CIES na condição de representante das gestões municipais, quatro participavam pela primeira vez e, nesse sentido, estavam num período de 'engajamento' político na causa da educação em saúde, pois a permanência na Comissão dependeria de uma opção pessoal, mas, também e principalmente, da escolha da gestão municipal (uma nova gestão poderia mudar a representação).

Os demais entrevistados, ou seja, os representantes das gestões municipais, representantes dos movimentos sociais e trabalhadores da saúde não somente atuavam há mais tempo na CIES (alguns deles, inclusive, desde a sua criação em 2007), mas, também, tinham uma atuação política (através dos movimentos sociais, como trabalhadores de saúde, mesmo a partir da CIES) comprometida com a discussão e com a implementação de políticas públicas de educação em saúde na Região 28. Esses representantes da CIES não somente estavam engajados, mas, efetivamente, militavam no campo da educação em saúde. A participação destes na CIES transcendia a própria Comissão; havia mesmo uma dedicação sociopolítica, concretizada em diferentes áreas de atuação, que compreendia envolvimento pessoal, uma trajetória de atuação, uma socialização que envolvia experiências, posicionamentos, saberes, práticas, interações no campo da educação em saúde, e que os tornava sujeitos em dinâmicas de construção de políticas públicas de educação em saúde.

As entrevistas realizadas seguiram um roteiro, em que algumas questões foram estabelecidas como norteadoras do diálogo, em especial aquelas que sugeriam relatos sobre as trajetórias de atuação política no campo da saúde (e na CIES). Nessa direção, inclusive, os entrevistados registraram que a condição de militante tem uma relação forte em suas trajetórias, as quais contribuíram para que, pela participação, organização, ações e mobilizações, se estruturasse um modo de agir coletivo, que afirma valores e identidade sociopolítica. 
(...) Aí é que eu me coloco como militante, pois ao participar pela primeira vez desse processo, eu empunhei a bandeira, posso dizer assim, eu assumi esse movimento de luta por um SUS, por um processo de trabalho de educação permanente dentro do sistema, que me engajo agora (Beatriz, representante do movimento estudantil).

A inserção dos sujeitos em espaços participativos, somada à formação acadêmica que alguns deles acessaram, foi importante para que desenvolvessem uma motivação para a militância na área da saúde; e contribuísse para que a formação política se constituísse a partir de experiências adquiridas no próprio movimento estudantil que, junto com as experiências acadêmicas, facilitou a identificação com a educação permanente em saúde.

O VERSUS foi um marcador pra minha formação e de um movimento de militância que a gente já fazia no diretório acadêmico que era inserir a discussão em saúde coletiva, de como que o curso de psicologia estaria inserido com a comunidade, com o MST, com a discussão de gênero, enfim, pensando essas discussões mais amplas, em termos de uma militância social, digamos assim (Elenara, representante de docentes da área de saúde).

A militância, nesse sentido, está vinculada a trajetórias biográficas que, em determinados momentos, inseriram esses sujeitos em experiências motivadoras para a mobilização política, para a definição da importância de comprometimento com determinadas causas, para a autoafirmação como sujeitos sociais e políticos, através da inserção nas mobilizações e nas lutas implicadas na defesa dessas causas. Nesse contexto, a participação na CIES aparece como uma consequência desse compromisso que vai sendo gestado nas trajetórias de reflexão e de mobilização coletivas.

Esta questão da militância é bem interessante. A gente constrói isso como pessoa, questão de vida, está dentro de nossa personalidade (...). Nós acreditamos que quando a comunidade participa do processo e constrói junto, ela vai também se qualificar no processo e trazer a sua necessidade pra qualificar o próprio processo (Cellinha, representante da $13^{a}$ Coordenadoria Regional de Saúde).

Em contrapartida, a militância proporciona crescimento pessoal e profissional. Pela militância, os integrantes da CIES afirmaram que ela representou um marco, um 'divisor de águas' em suas vidas, ao vivenciarem mudanças na área da saúde que trouxeram oportunidade de mudar, crescer, tanto pessoal quanto profissionalmente (Oliveira, 2005). Com a militância, eles adquiriram respeito e conhecimentos, ampliaram seus relacionamentos interpessoais e se realizaram como seres políticos e sociais. 
Quando eu consigo perceber que a minha graduação era uma até eu ter uma vivência do VERSUS, e depois ela passou a ser outra. Eu não podia me enxergar como uma estudante de psicologia. Passei a me enxergar como uma estudante de curso da área da saúde. Foi outra visão. Teve uma mudança (Cida, representante de trabalhadores estaduais de saúde).

A CIES da Região 28 de Saúde se constrói como uma militância que estrutura suas ações na implementação da política de educação permanente em saúde. Nesse sentido, ao considerar a metodologia proposta pela teoria do 'ciclo de políticas públicas', cabe recolocar a questão e tomar as manifestações dos entrevistados como referência principal para a compreensão dos diferentes momentos da construção da política, desde a identificação dos problemas, a formação da agenda, a formulação de alternativas, o processo de tomada de decisões, até a execução e, mesmo, a avaliação das políticas de educação em saúde na Região

A condução da Política de Educação Permanente em Saúde por meio da CIES é orientada por estratégias e práticas teóricas e políticas que pretendem estar vinculadas às políticas do SUS, propondo-se o fortalecimento das lutas sociais, tal como sugerido pelo Plano de Ação Regional de Educação Permanente em Saúde, em todos os momentos da construção das políticas (Brasil, 2007).

A importância que a militância tem na 'identificação dos problemas' está nas descobertas de necessidades de educação em saúde e nos vazios de conhecimento institucionais. Róvere (1993) define como 'problema' a brecha entre uma realidade e um desejo acerca de como deveria ser essa realidade para um determinado observador (Róvere, 1993, p. 79). A partir desta perspectiva, o autor ressalta que os problemas não existem independentemente dos sujeitos que o problematizam, mas emergem pelo caráter subjetivo de conhecer, pensar e colocar em questão a transformação das práticas do trabalho (Róvere, 1993).

Ao ser apresentada para os participantes da CIES, a questão foi entendida como 'problemas' que a própria Comissão enfrenta para organizar suas atividades. Inclusive elencaram alguns, apontando para diferentes tipos de dificuldades encontradas no encaminhamento das ações, na relação que estabelecem tanto com os municípios quanto com outras instâncias governamentais.

É uma burocracia que aí não envolve só a CIES, mas pelas outras instâncias que tem que percorrer, como a CIR e CIB, e assim garantir lugar na CIR pra ser aprovado ou não e (...) depois disso parece que tranca e é muito complicado fazer isso andar (...) (Beatriz, representante do movimento estudantil).

O não entendimento da política por parte dos gestores em saúde dos municípios da região. Eu acredito mais no desconhecimento do que pelo conhecimento, até pelo 
conceito de saúde que a gente trabalha (...). É quem está lá no dia a dia, na ponta e que percebe as dificuldades (...) (Duda, trabalhadora em saúde).

Os problemas identificados pelos entrevistados exigem estratégias específicas de pactuação entre os gestores, mesmo de mudanças na concepção de educação e de determinadas formas de atuação dos profissionais da saúde. Na perspectiva dos entrevistados, a qualificação e a formação são importantes, principalmente porque ajudam a compreender que a reflexão sobre o cotidiano de atuação nos espaços de realização dos serviços de saúde é um 'ato pedagógico' (de aprendizagem) na construção de soluções aos problemas por eles vivenciados nesse mesmo cotidiano de trabalho.

A forma como a pergunta relacionada à identificação dos problemas foi compreendida pelos entrevistados permitiu perceber que, para eles, 'problemas' se relacionam com questões importantes e vinculadas, muitas vezes, a dificuldades que a própria Comissão identifica quando discute a realidade da saúde na Região. Nesse sentido, há a compreensão de que a CIES tem grande importância na 'identificação de problemas' que sustentam a própria elaboração de uma agenda de atuação no campo da educação permanente em saúde.

A 'definição da agenda' determina o processo de decisão dos governos, no que diz respeito à constituição de um problema e quais ações de política pública serão resolvidas. Surge quando são listadas as questões ou problemas que inquietam aos agentes governamentais e outros membros da sociedade, em certo momento implicando que o governo reconheça que um determinado problema é uma questão 'pública' e merece a sua atenção (Arretche, 1999).

É importante destacar que, mesmo que determinadas agendas sejam consideradas importantes pelos trabalhadores da saúde ou mesmo por participantes da CIES, uma vez encaminhadas para as instâncias de decisão governamental, não necessariamente se transformam em agendas públicas. E nem sempre os gestores públicos têm sensibilidade para ouvir a própria CIES na definição das agendas públicas de educação permanente em saúde.

A gente percebe uma desqualificação em relação à educação em saúde, onde o profissional não é ouvido da forma que deveria, se isso será colocado como pauta de agenda pelo gestor dos processos de trabalho, dos serviços de saúde? Só se houver muita pressão dos membros da CIES (Duda, trabalhadora em Saúde).

Não dá para desconsiderar que a CIES constitui um espaço privilegiado de debates e de sistematização dos problemas e das propostas constituídas pela militância e outros profissionais que representam a gestão de saúde nos municípios. E que, inclusive, tem autonomia para definir ações e/ou propor projetos. No entanto, no que diz respeito às prioridades na agenda governamental, nem sempre os participantes da CIES têm condições de interferir de 
modo significativo. O próprio caráter consultivo da CIES coloca limitações em sua atuação.

A inclusão de um problema na agenda de políticas públicas é apenas um começo. Ele ainda precisa de outras etapas nesse processo. A política é pra fazer a gestão, ela está na agenda a partir de uma discussão do Conselho Nacional de Saúde que conseguiu um espaço dentro da Secretaria de Gestão do Trabalho e da Educação na Saúde (Cellinha, representante da $13^{\mathrm{a}} \mathrm{CRS}$ ).

O depoimento manifesta indícios de conflitos em relação às prioridades da educação em saúde. A maioria desses conflitos confronta os militantes da CIES, muitas vezes ao propor ações com base na atenção a problemas estruturais de qualificação dos trabalhadores de saúde. E os gestores municipais, mais preocupados com o atendimento de demandas de curto prazo, tendem a definir suas prioridades a partir de suas próprias realidades municipais.

Nessa dinâmica de construção de políticas públicas, ao se pensar na 'formulação das alternativas', na medida em que uma agenda é estabelecida, torna-se necessário definir as linhas de ação que serão adotadas com vistas a enfrentar os problemas identificados.

Há uma disposição legislativa de que todo o processo de construção das políticas públicas ocorra de forma cooperativa e envolva não somente agentes governamentais, mas, também, a sociedade civil organizada. Nesse sentido, o desenvolvimento e a formulação da Política de Educação Permanente em Saúde devem (ou deveriam) se constituir pelos diversos atores sociais que compõem a CIES, levando em consideração as especificidades da região no que referem à educação em saúde para a elaboração do Plano de Ação Regional de Educação Permanente em Saúde. Portanto, este é o momento em que é reconhecida a importância que essa militância tem na 'formulação de alternativas' da política de educação permanente, pois o fortalecimento da participação intersetorial e coletiva contempla a representatividade e os interesses dos diversos segmentos no SUS e o compromisso dos gestores neste processo (Brasil, 2007).

Refere-se ao processo de gerar, de criar um conjunto de escolhas, de políticas plausíveis para resolver problemas. E com isso surge uma gama de potenciais, de escolhas de políticas que são identificadas como ferramentas ou instrumentos de políticas públicas de governo, os meios pelos quais os governantes se utilizam para implementar as políticas. (Cellinha, representante da $13^{\mathrm{a}} \mathrm{CRS}$ ).

Este depoimento deixa claro que a CIES tem importância fundamental na formulação de alternativas, como um espaço de reflexão sobre as necessidades, sobre os problemas, sobre as agendas e, também, sobre as alternativas 
de ações, que muitas vezes resultam em projetos, encaminhados pela própria CIES, que, uma vez recebendo recursos financeiros, são executados nos municípios e na Região.

O processo decisório na Política de Educação Permanente em Saúde na Região 28 exige o envolvimento dos sujeitos, o que, pela própria legislação, define a importância da participação popular na construção das políticas públicas. É instituído em espaços organizativos, com encontros e debates, onde os atores representativos são a Comissão Intergestores Regional (CIR) e a própria CIES. No entanto, a CIES tem apenas poder consultivo, não é, portanto, a instância na qual as decisões são tomadas.

Agora o processo decisório (...) passa além da CIES, a educação permanente passa pela CIES e passa por este órgão de gestão que é a CIR, um colegiado regional que tem também a responsabilidade de decisão, de tomada de decisão como uma função de política pública em que se decide ou não por uma determinada ação (Cellinha, representante da $13^{\mathrm{a}} \mathrm{CRS}$ ).

As decisões são tomadas no Colegiado de Gestão Regional. Mas os participantes da CIES se fazem presentes naquele Colegiado e, através de negociações, embates, pressões, também procuram definir estratégias de ação, pois como em qualquer processo decisório, existe necessidade de interação, negociação, pactuações entre os diversos segmentos que compõem tanto a CIES quanto a CIR. A democratização do processo decisório da Política de Educação Permanente em Saúde é, portanto, um processo que se dá mediante tensionamentos entre as duas comissões, no entanto, o espaço é considerado privilegiado, pois contribui significativamente para a qualificação do processo decisório.

A 'fase de implementação' de uma política pública compreende o momento da sua execução. É importante entender como se configura o seu contexto na política pública em questão e, especialmente, o envolvimento de atores comprometidos com a política. Entre essas configurações estão o estabelecimento de metas a atingir, a natureza dos problemas que envolvem a implementação, as ideias que os atores têm no que diz respeito à solução desses problemas, considerando o contexto político em que estão inseridos (Flexor e Leite, 2006).

A implementação efetiva da Política Nacional de Educação Permanente em Saúde está a cargo dos municípios, principalmente das secretarias municipais de saúde, desde a sua adesão pela assinatura do Termo de Compromisso através do Pacto de Saúde (Brasil, 2006). No entanto, as normas, regulamentos e orientações foram decididos em instância federal, mediante ampla negociação com outros níveis de governos e entidades como as CIR e CIES em âmbito regional regulamentado pelo Plano de Ação Regional de Educação Permanente em Saúde. 
No que diz respeito à importância da CIES na implementação da Política de Educação Permanente da Região, os participantes da entrevista contextualizaram que a CIES tem não apenas responsabilidades, mas tem também potenciais para fortalecer o processo de empoderamento dos militantes, em seus diferentes espaços de intersecção, na participação efetiva da construção e na implementação da política pública. A CIES é percebida, nesse sentido, como uma possibilidade viável para promover a sensibilização para a mudança nas ações desenvolvidas no ensino e no trabalho cotidiano, conforme indica o seguinte depoimento:

A instituição dos Numescs (Núcleos Municipais de Saúde Coletiva) nos municípios é um processo conhecido pelas políticas públicas aqui na região como implementação. Dinâmico, traduzido em ações, importante para a sua eficácia e onde são produzidos os resultados concretos da política pública. Então ele [Numesc] vai precisar atender o que aparece no plano regional como necessário (...). (Cellinha, representante da $13^{\mathrm{a}} \mathrm{CRS}$ ).

Essas ações podem ser consideradas uma busca constante de estratégias, que servem para analisar e implementar o processo de trabalho de educação permanente em saúde desenvolvido no interior da CIES. Podem contribuir, também, para o processo de desvelamento crítico, tão importante para que os sujeitos sociais possam perceber a política como uma estratégia que busca a formação dos profissionais da saúde, além da própria mudança dos serviços segundo a lógica da integralidade (Ceccim, 2005).

Quanto à 'etapa da avaliação das políticas' de educação permanente em saúde, a sua configuração ocupa um espaço de fundamental importância pela dimensão regional, além das demais fases do 'ciclos das políticas'.

Dentre as várias definições e modelos atribuídos à avaliação de políticas públicas, destacadas por Viana (1988), a avaliação de impacto da política (considerado ex-pos - pois ocorre durante e depois da fase de implementação) é entendida como o modelo que mais se adequa à proposta do plano de ação de educação permanente em saúde, tal como observado nas ações da CIES na Região 28. No sentido de acompanhar as suas propostas, a CIES estabeleceu um sistema de monitoramento e de avaliação das ações desenvolvidas e dos projetos executados, com base nos problemas enfrentados na realidade, levando em consideração os conhecimentos e as experiências adquiridas e oferecendo elementos para a construção de disposições e engajamento, percebidos no seguinte depoimento:

O plano de ação de educação permanente em saúde já prevê uma avaliação constante e uma das responsabilidades, fazer avaliação de cada atividade pelas pessoas que participarem (...) Aí a instituição, com a nossa participação, vai criar um 
modelo de avaliação. Mas também nós, 'o povo da CIES', os 'militantes da CIES' temos esse compromisso de dar o retorno aos gestores (Thamy, representante da $\left.13^{\mathrm{a}} \mathrm{CRS}\right)$.

A importância da militância pela experiência adquirida é fundamental para a análise avaliativa da política de educação em saúde da CIES da Região. O monitoramento e a avaliação de impacto das ações desenvolvidas, de forma sistêmica, norteiam as futuras ações de formação dos profissionais de saúde e levam em consideração a construção de indicadores que possibilitam realizar o levantamento das necessidades e o estabelecimento de metas para a qualificação e a habilitação de profissionais para o SUS, e estas devem ser articuladas com a necessidade local e regional.

\section{Considerações finais}

Este artigo teve por objetivo analisar a importância da CIES da Região 28 de Saúde, no Rio Grande do Sul, na construção de políticas públicas de educação permanente em saúde. A CIES da Região de Saúde é um importante espaço de condução da Política de Educação Permanente em Saúde, orientada por estratégias e práticas teóricas e políticas que pretendem estar vinculadas com as políticas do Sistema Único de Saúde, com o fortalecimento das lutas sociais e em respeito à vida dos cidadãos. Embora a CIES seja constituída com funções consultivas, por representações tanto do governo quanto de diferentes segmentos da sociedade civil organizada, a sua importância tem se colocado tanto no campo da mobilização, da discussão, da provocação para a formulação de políticas, quanto na execução de ações, no acompanhamento das políticas (em nível municipal e em nível regional) e da própria fiscalização das políticas regionais de educação permanente em saúde.

Cabe, por fim, destacar que a CIES da Região 28 de Saúde tem realizado um trabalho relevante e desafiador no sentido de buscar a reorganização dos processos de trabalho a partir da realidade local e regional, merecendo atenção e destaque no âmbito da construção de políticas públicas de educação em saúde. E, além disso, é importante a investigação e a discussão, para que se torne tema cada vez mais presente no cotidiano dos serviços, nos quais devem ser realizados outros estudos com o intuito de analisar, problematizar e aprofundar novas formas de compreensão de educação em saúde. Nesse sentido, inclusive, espera-se que o estudo aqui apresentado possa impulsionar discussões e novos estudos sobre a CIES em outras regiões do país. 


\section{Colaboradores}

Maria Raquel Pilar Steyer foi responsável pela concepção, delineamento do estudo, análise e interpretação dos dados, redação do artigo e aprovação da versão final. Marco André Cadoná participou da concepção e delineamento do estudo, revisão crítica e aprovação da versão final. Não há conflito de interesses.

Resumen El artículo presenta un análisis de la importancia de la militancia en la construcción de una política pública regional de la formación continua. Con referencia a las actividades políticas de los participantes en la Comisión de Integración Docencia-Servicio (CIES) en la Región 28 de la Salud en Rio Grande do Sul, Brasil, el análisis da atención al espacio político que los participantes del CIES ocupan no sólo en la articulación política, sino también en sus propias acciones de aplicación relacionadas con la educación para la salud en curso en la región estudiada. Bajo el punto de vista metodológico, la investigación se basó en dos procedimientos principales: estudio y análisis de datos secundarios, que cubre la legislación relativa a la educación de las políticas y la estructura del CIES salud continua; la realización de entrevistas semi-estructuradas con los participantes del CIES de la Región 28 de Salud. Como resultado se encontró que aunque el CIES ha sido establecido por la legislación sólo con funciones de asesoramiento dentro de las regiones sanitarias, las acciones comprometidas de los participantes en la Región 28 de Salud puede hacer que sea un espacio importante (regional) de militancia y de la implementación de políticas de formación permanente en materia de salud.

Palabras clave militancia; políticas públicas; regionalización de la salud; la educación sanitaria.

\section{Notas}

${ }^{1}$ Universidade de Santa Cruz do Sul, Programa de Pós-Graduação de Desenvolvimento Regional, Santa Cruz do Sul, Rio Grande do Sul, Brasil.

$<$ raquel.steyer@gmail.com>

Correspondência: Travessa Rodolfo Moreira de Souza, 59, Centro, CEP 96640-000, Rio Pardo, Rio Grande do Sul, Brasil.

${ }^{2}$ Universidade de Santa Cruz do Sul, Programa de Pós-Graduação de Desenvolvimento Regional, Santa Cruz do Sul, Rio Grande do Sul, Brasil.

$<$ mcadona@unisc.br>

${ }^{3}$ A referida Região de Saúde é constituída por 13 municípios: Santa Cruz do Sul, Gramado Xavier, Herveiras, Sinimbu, Mato Leitão, Candelária, Vale do Sol, Vera Cruz, Venâncio Aires, Passo do Sobrado, Vale Verde, Rio Pardo e Pântano Grande (Rio Grande do Sul, 2012).

${ }^{4}$ Este artigo é resultado de dissertação de mestrado de Maria Raquel Pilar Steyer, intitulada Militância e politicas de educação em saúde: uma análise a partir da CIES (Comissão de Integração Ensino-Serviço) na Região 28 de Saúde RS, visão dos atores, apresentada ao Programa de Pós-Graduação de Desenvolvimento Regional da Universidade de Santa Cruz do Sul (Unisc), em 2016. 


\section{Referências}

ARRETCHE, Marta. Políticas sociais no Brasil: descentralização em um estado federativo. Revista Brasileira de Ciências Sociais, v. 14, n. 40, p. 111-141, 1999.

BRASIL. Decreto n. 7. 508, de 28 de junho de 2011. Regulamenta a lei n. 8.080 de 12 de setembro de 1990 para dispor sobre a organização do Sistema Único de Saúde - SUS, o planejamento da saúde, a assistência à saúde e a articulação interfederativa, e dá outras providências. Diário Oficial da União, Poder Executivo, Brasília, DF, 29 jun. 2011. Seção I, p. 1.

BRASIL. Ministério da Saúde. Portaria n. 399/ GM/MS, de 22 de fevereiro de 2006. Divulga o Pacto pela Saúde 2006 - Consolidação do SUS e aprova as Diretrizes Operacionais do Referido Pacto. Diário Oficial da União, Poder Executivo, Brasília, DF, 23 fev. 2006. Seção I, p. 43- 51.

BRASIL. Ministério da Saúde. Portaria n.1.996/ GM/MS, de 20 de agosto de 2007. Dispõe sobre as diretrizes para a implementação da Política Nacional de Educação Permanente em Saúde. Diário Oficial da União, Poder Executivo, Brasília, 22 ago. 2007, Seção I, p. 34-38.

CECCIM, Ricardo B. Educação permanente em saúde: descentralização e disseminação de capacidade pedagógica na saúde. Ciência \& Saúde Coletiva, Rio de Janeiro, v. 10, n. 4, p. 975-986, out.-dez. 2005.

ESCOREL, Sarah. História das políticas de saúde no Brasil de 1964 a 1990: do golpe militar à reforma sanitária. In: GIOVANELLA, Lígia. et al. (orgs.). Políticas e sistemas de saúde no Brasil. Rio de Janeiro: Editora Fiocruz, 2008. p. 323-364.

FLEXOR, Georges; LEITE, Sérgio P. Análise de políticas públicas: breves considerações teórico-metodológicas. In: ENCONTRO NACIONAL DE POLÍTICA, 12., 2007, São Paulo. Anais... São Paulo, 2007. (Subárea 4: Economia e Estado - Sessão Ordinária, 2006).

OLIVEIRA, Wilson J. F. Paixão pela natureza: atuação profissional e participação na defesa de causas ambientais no Rio Grande do Sul entre 1970 e início dos anos 2000. 464 f. Tese
(Doutorado em Antropologia) - Instituto de Filosofia e Ciências Humanas, Universidade Federal do Rio Grande do Sul, Porto Alegre, 2005.

PAIM, Jairnilson S. A reforma sanitária brasileira e o Sistema Único de Saúde: dialogando com hipóteses concorrentes. Physis: Revista de Saúde Coletiva, Rio de Janeiro, v. 18, n. 4, p. 625-644, 2008.

PINTO, Isabela C. M. Mudanças nas políticas públicas: a perspectiva do ciclo de política. Revista de Políticas Públicas, São Luiz, v. 12, n. 1, p. 27-36, jan.-jun. 2008.

REIS, Eliana T. Contestação, engajamento e militantismo: da luta contra a ditadura à diversificação das modalidades de intervenção política no Rio Grande do Sul. 2007. 330 f. Tese (Doutorado em Ciência Política) - Instituto de Filosofia e Ciências Humanas. Universidade Federal do Rio Grande do Sul, Porto Alegre, 2007.

RIO GRANDE DO SUL. Secretaria Estadual de Saúde. CIB/RS. Resolução n. 555/12, de 19 de setembro de 2012. Altera a configuração e a quantidade de Regiões de Saúde no Rio Grande do Sul, e institui as Comissões Intergestores Regionais - CIR. Porto Alegre, 2012.

RÓVERE, Mario R. Planificación estratégica de recursos humanos em salud. Programa de Desarrollo de Recursos Humanos em Salud. Washington, D.C.: Organización Panamericana de La Salud, 1993. (Serie Desarrollo de Recursos Humanos em Salud n. 96)

SECCHI, Leonardo. Politicas públicas: conceitos, esquemas de análise, casos práticos. 2. ed. São Paulo: Cengage Learning, 2013.

SOUZA, Celina. Políticas públicas: uma revisão da literatura. Sociologias, Porto Alegre, v. 8, n. 16, p. 20-45, jul.-dez. 2006.

VIANA, Ana L. Abordagens metodológicas em políticas públicas. Revista de Administração Pública, Rio de Janeiro, v. 30, n. 2, p. 5-43, mar-abr., 1996.

Recebido em 01/07/2016. Aprovado em 29/01/2017. 